\title{
Comparison of haemodynamic response to laryngoscopy and endotracheal intubation following induction of general anaesthesia with propofol or etomidate
}

\author{
Devaraj I. C. ${ }^{1}$, Manjunath Timmappa Bhat ${ }^{2, *}$, Shrirang V. Torgal ${ }^{3}$ \\ ${ }^{1}$ Assistant Professor, ${ }^{2}$ Associate Professor, ${ }^{3}$ Professor, Dept. of Anaesthesia, ${ }^{1}$ Vijayanagara Institute of Medical Sciences, \\ Bellary, Karnataka, ${ }^{2}$ Karwar Institute of Medical Sciences, Karwar, Karnataka, SDM Medical College, Dharwad, Karnataka, \\ India
}

*Corresponding Author:

Email:drmnb05@gmail.com

Received: $14^{\text {th }}$ September, 2017

Accepted: $20^{\text {th }}$ November, 2017

\begin{abstract}
Aims and Objectives: Propofol and etomidate are most frequently used intravenous induction agents, with very similar onset of action and duration of action, few advantages over each other and few unwanted effects. Recent studies and reintroduction of etomidate has paved way for its routine use in haemodynamically unstable patients.

Materials and Methods: One hundred patients belonging to American Society of Anaesthesiologists (ASA) class I and II, aged between 18 to 60 years scheduled to undergo elective surgical procedure under general anaesthesia were selected. All the patients received tablet diazepam $0.2 \mathrm{mg} / \mathrm{kg}$ as premedication and fentanyl $2 \mathrm{mcg} / \mathrm{kg}$ body weight before induction. Patients were be randomly allocated to group $\mathrm{P}((n=50)$, who received propofol $2 \mathrm{mg} / \mathrm{kg}$ or group $\mathrm{E}(n=50)$ who received, Etomidate $0.3 \mathrm{mg} / \mathrm{kg}$ as induction agent for general anaesthesia. Endotracheal intubation was facilitated by vecuronium $0.1 \mathrm{mg} / \mathrm{kg}$ body weight. Heart rate (HR), Systolic blood pressure (SBP), diastolic blood pressure (DBP) and mean arterial blood pressure (MAP) were recorded at basal, after fentanyl, 1, 3, 5 and 10 min following induction.

Results: There was no significant change in the heart rate at and after the induction, intubation in either group $\mathrm{P}$ or group E. There was significant decrease in SBP, DBP and MAP in group P following induction, whereas there was less decrease in Group E. There was increase in the SBP, DBP and MAP after intubation in both the groups, but in group P it did not increase above the basal and remained below the basal levels at 5 and 10 minutes following intubation.

Conclusion: Etomidate provides stable haemodynamics at induction of general anaesthesia. But it does not attenuate the haemodynamic response to laryngoscopy and intubation. Propofol causes significant hypotension at induction and attenuates the pressor response to laryngoscopy and intubation.
\end{abstract}

Keywords: Propofol, Etomidate, Haemodynamic, Laryngoscopy, Blood pressure.

\section{Introduction}

Invention of anaesthesia, a way of relief of pain during surgery has been the greatest invention of human kind. From the first day of anaesthesia for dental extraction in 1841, public demonstration of anaesthesia to the world by WTG Morton on $16^{\text {th }}$ October 1846, anaesthesia has developed in all spectrums to the modern anaesthesia.

The efforts of the human kind to manage pain have taken a leap apart. The efforts in the search of methods and drugs which have the minimal effect on human physiology have been a continuous process. Most of the anaesthetic agents used today are cardiovascular and respiratory depressants. In many elective and emergency surgeries patients present with haemodynamic instability. So the management of these patients poses a great challenge to anaesthesiologists.

Propofol is an ultra-short-acting intravenous induction agent with some favourable properties like smooth induction, quick recovery and antiemetic properties. It is deemed not a suitable agent in patients with cardiovascular instability and shock as it decreases blood pressure, cardiac output and systemic vascular resistance due to inhibition of sympathetic vasoconstriction and impairment of baroreceptor reflex regulatory system. This effect may be exaggerated in hypovolemic and elderly patients with compromised left ventricular function due to coronary artery disease. It produces dose dependent depression of ventilation. However, the adverse effects such as pain on injection, thrombophlebitis and myoclonus have been reduced by using reformulated lipofundin (lipuro) solution and pretreating with fentanyl, an opioid. ${ }^{1}$

Etomidate is one of the induction agents which is claimed to be cardiostable and had gained lot of popularity in the past and fell out of use due to adrenocortical suppression. Further studies in the recent years on etomidate have yielded a promising results and it has regained its popularity as a safe anesthetic and more so in sepsis and critically ill patients who are haemodynamically unstable. ${ }^{2}$ Although eto- midate can cause adrenal insufficiency in these patients in postoperative period, clinical consequence of that is still unclear over its advantage to prevent hypotension at induction. $^{3-5}$

Considering the common use of propofol and etomidate for induction of general anaesthesia, the primary objective of our randomized clinical study was to compare the haemodynamic response to 
laryngoscopy and endotracheal intubation and secondary objectives like pain on injection, myoclonus, postoperative nausea and vomiting.

\section{Materials and Methods}

This study was conducted in 100 patients of ASA physical status I and II aged between 18-60 years undergoing elective surgeries under general anaesthesia. After obtaining the clearance from the institutional ethical committee, informed and written consent was obtained from the patients. Patients were be randomly allocated to group $\mathrm{P}$, who received propofol $2 \mathrm{mg} / \mathrm{kg}$ or group E who received, Etomidate $0.3 \mathrm{mg} / \mathrm{kg}$ as induction agent for general anaesthesia.

Exclusion Criteria included those who are aged less than 18 and more than 60 years, emergency surgeries, patients with history of epilepsy, patients on steroid medication, presence of adrenal harmone insufficiency, those with known allergy to propofol and etomidate or to any of the constituents of emulsion, presence of any cardiovascular disorder.

All the patients were fasted 6 hours for solids, 4 hours for liquids and 2 hours for clear fluids and received tablet diazepam $10 \mathrm{mg}$ and tablet ranitidine $150 \mathrm{mg}$ the night before and on the morning of surgery.

Venous access was established with 20 G intravenous cannula on the dorsum of the nondominant hand and an infusion of normal saline was started. Patients were connected to a multipara meter monitor and base line values of heart rate, systolic blood pressure, diastolic blood pressure, mean arterial blood pressure and oxygen saturation were recorded. Fentanyl $2 \mu \mathrm{g} / \mathrm{kg}$ was given IV and vital parameters were recorded after $2 \mathrm{~min}$.
Patient was pre-oxygenated with $100 \%$ oxygen for 3 minutes and general anaesthesia was induced with either propofol $2 \mathrm{mg} / \mathrm{kg}$ or etomidate $0.3 \mathrm{mg} / \mathrm{kg}$ given over 30- 60 seconds. After the induction, vital parameters were recorded; pain on injection, myoclonus and ease of mask of ventilation were noted. Vecuronium $0.1 \mathrm{mg} / \mathrm{kg}$ was given to facilitate endotracheal intubation. Intubation was done with appropriate sized endotracheal tubes 3 minutes after the induction of anaesthesia. Hemodynamic parameters were recorded at $1,3,5$ and 10 minutes. After intubation, anaesthesia was maintained with nitrous oxide and isoflurane and vecuronium was used for muscle relaxation. Patient was followed up for the incidence of post-operative nausea and vomiting.

\section{Statistical analysis}

Continuous variables data were presented as mean \pm SD and nominal variable as number and percentage. The Chi square test was used for comparison of categorical variables and unpaired t test for continuous variables. Clinical data were statistically analysed by using software SPSS IBM version 20. P value $<0.05$ was considered as significant.

\section{Results}

In our study there were no statistical differences between the two groups with respect to age and sex distribution. The mean weight of the patients in the Group P was $62.58 \mathrm{~kg}$ and in group E was $55.40 \mathrm{~kg}$ which was statically significant with a $p$ value of 0.004 . This was not clinically significant and no patient was low weight for their height in both the groups.

Table 1: showing the changes in the mean heart rate

\begin{tabular}{|c|c|c|c|c|c|c|}
\hline & Group & $\begin{array}{c}\text { Mean } \\
\text { HR bpm }\end{array}$ & $\begin{array}{c}\text { Std. } \\
\text { Deviation }\end{array}$ & \begin{tabular}{|c|} 
Std. Error \\
Mean
\end{tabular} & $\begin{array}{l}\text { T test- } \\
\text { value }\end{array}$ & P-value \\
\hline \multirow{2}{*}{$\begin{array}{c}\text { Basal } \\
\text { HR }\end{array}$} & Group P & 82.940 & 14.2448 & 2.0145 & \multirow{2}{*}{2.249} & \multirow{2}{*}{$0.027^{*}$} \\
\hline & Group E & 76.820 & 12.9295 & 1.8285 & & \\
\hline \multirow{2}{*}{$\begin{array}{c}\text { After } \\
\text { Fentanyl }\end{array}$} & Group P & 83.040 & 14.2614 & 2.0169 & \multirow{2}{*}{2.132} & \multirow{2}{*}{$0.036^{*}$} \\
\hline & Group E & 76.720 & 15.3650 & 2.1729 & & \\
\hline \multirow{2}{*}{1 minute } & Group P & 78.060 & 12.6723 & 1.7921 & \multirow{2}{*}{1.734} & \multirow{2}{*}{0.086} \\
\hline & Group E & 73.460 & 13.8331 & 1.9563 & & \\
\hline \multirow{2}{*}{3 minute } & Group P & 83.860 & 12.4475 & 1.7603 & \multirow{2}{*}{0.078} & \multirow{2}{*}{0.938} \\
\hline & Group E & 83.640 & 15.5940 & 2.2053 & & \\
\hline \multirow{2}{*}{5 minute } & Group P & 84.840 & 13.3636 & 1.8899 & \multirow{2}{*}{1.156} & \multirow{2}{*}{0.250} \\
\hline & Group E & 81.740 & 13.4465 & 1.9016 & & \\
\hline \multirow{2}{*}{$10 \mathrm{~min}$} & Group P & 78.720 & 17.1584 & 2.4266 & \multirow[b]{2}{*}{0.761} & \multirow[b]{2}{*}{0.448} \\
\hline & Group E & 76.440 & 12.4182 & 1.7562 & & \\
\hline
\end{tabular}

The comparison of heart rate changes was done between two groups at 13,5 and 10 minutes following induction. The heart changes were statistically insignificant between the two groups. 
Table 2: Showing the changes in mean systolic blood pressure

\begin{tabular}{|c|c|c|c|c|c|c|}
\hline & Group & $\begin{array}{c}\text { Mean } \\
\text { SBP in } \mathbf{m m} \\
\quad \text { Hg }\end{array}$ & $\begin{array}{c}\text { Std. } \\
\text { Deviation }\end{array}$ & $\begin{array}{c}\text { Std. Error } \\
\text { Mean }\end{array}$ & $\begin{array}{l}\text { T test- } \\
\text { value }\end{array}$ & P-value \\
\hline \multirow{2}{*}{$\begin{array}{c}\text { Basal } \\
\text { SBP }\end{array}$} & Group P & 129.060 & 10.2547 & 1.4502 & \multirow{2}{*}{3.916} & \multirow{2}{*}{$0.000^{*}$} \\
\hline & Group E & 120.880 & 10.6285 & 1.5031 & & \\
\hline \multirow{2}{*}{$\begin{array}{c}\text { After } \\
\text { Fentany }\end{array}$} & Group P & 124.000 & 10.6579 & 1.5073 & \multirow{2}{*}{3.077} & \multirow{2}{*}{$0.003^{*}$} \\
\hline & Group E & 117.260 & 11.2410 & 1.5897 & & \\
\hline \multirow[t]{2}{*}{$1 \min \mathrm{A}]$} & Group P & 96.560 & 10.5910 & 1.4978 & \multirow{2}{*}{5.551} & \multirow{2}{*}{$0.000^{*}$} \\
\hline & Group E & 109.840 & 13.1899 & 1.8653 & & \\
\hline \multirow[t]{2}{*}{$3 \min A$} & Group P & 121.240 & 19.5088 & 2.7590 & \multirow{2}{*}{2.457} & \multirow{2}{*}{$0.016^{*}$} \\
\hline & Group E & 129.380 & 12.9676 & 1.8339 & & \\
\hline \multirow[t]{2}{*}{$5 \min \mathrm{A}$} & Group P & 121.240 & 14.8455 & 2.0995 & \multirow{2}{*}{3.592} & \multirow{2}{*}{$0.001^{*}$} \\
\hline & Group E & 129.380 & 11.3057 & 1.5989 & & \\
\hline \multirow{2}{*}{$\begin{array}{c}10 \text { min } \\
\mathrm{AI}\end{array}$} & Group P & 99.280 & 14.5097 & 2.0520 & \multirow{2}{*}{3.482} & \multirow{2}{*}{$0.001^{*}$} \\
\hline & Group E & 108.240 & 10.9797 & 1.5528 & & \\
\hline
\end{tabular}

The change in mean systolic blood pressure throughout anaesthetic procedure was statistically significant as shown in the above table._One minute following induction, there was fall in systolic blood pressure by $25.18 \%$ in group $\mathrm{P}$ and $9.13 \%$ in group $\mathrm{E}$ which was statistically significant $(\mathrm{p}=0.000)$. At 3 min and 5 minutes SBP decreased by $6.06 \%$ where as in group E, SBP increased by $7.03 \%$ with statistical significance of 0.016 and 0.001 respectively. At 10 minutes there was fall in SBP by $23.07 \%$ in group $\mathrm{P}$ and by $10.46 \%(\mathrm{p}=0.001)$.

Table 3: showing the changes in the mean diastolic blood pressure (DBP)

\begin{tabular}{|c|c|c|c|c|c|c|}
\hline & Group & $\begin{array}{c}\text { Mean } \\
\text { DBP } \mathbf{m m ~ H g} \\
\end{array}$ & $\begin{array}{c}\text { Std. } \\
\text { Deviation }\end{array}$ & $\begin{array}{c}\text { Std. Error } \\
\text { Mean }\end{array}$ & $\begin{array}{l}\text { T test- } \\
\text { value }\end{array}$ & P-value \\
\hline \multirow{2}{*}{ DBP Basal } & Group P & 77.700 & 8.3891 & 1.1864 & \multirow{2}{*}{3.218} & \multirow{2}{*}{$0.002^{*}$} \\
\hline & Group E & 72.180 & 8.7591 & 1.2387 & & \\
\hline \multirow{2}{*}{$\begin{array}{l}\text { After } \\
\text { Fentanyl }\end{array}$} & Group P & 74.880 & 10.2612 & 1.4511 & \multirow{2}{*}{2.672} & \multirow{2}{*}{$0.009^{*}$} \\
\hline & Group E & 69.680 & 9.1706 & 1.2969 & & \\
\hline \multirow{2}{*}{1 min } & Group P & 56.980 & 10.5627 & 1.4938 & \multirow{2}{*}{2.780} & \multirow{2}{*}{$0.007^{*}$} \\
\hline & Group E & 62.860 & 10.5888 & 1.4975 & & \\
\hline \multirow{2}{*}{3 min } & Group P & 76.360 & 18.4167 & 2.6045 & \multirow{2}{*}{1.884} & \multirow{2}{*}{0.063} \\
\hline & Group E & 81.940 & 9.9804 & 1.4114 & & \\
\hline \multirow{2}{*}{$5 \min$} & Group P & 65.420 & 11.8513 & 1.6760 & \multirow{2}{*}{1.111} & \multirow{2}{*}{0.269} \\
\hline & Group E & 68.160 & 12.7861 & 1.8082 & & \\
\hline \multirow{2}{*}{$10 \mathrm{~min}$} & Group P & 58.380 & 10.6098 & 1.5004 & \multirow{2}{*}{1.084} & \multirow{2}{*}{0.281} \\
\hline & Group E & 60.620 & 10.0385 & 1.4197 & & \\
\hline
\end{tabular}

One minute after induction there was fall in the DBP by $26.67 \%$ in group $\mathrm{P}$ and by $12.91 \%$ in group E which was significant with $p$ value of 0.007 . At 3 minutes (laryngoscopy and intubation) there was fall in DBP by $1.72 \%$ in group $\mathrm{P}$ whereas there was an increase in group $\mathrm{E}$ by $13.52 \%$ which was not statistically significant $(\mathrm{p}=0.063)$. At $5 \mathrm{~min}$ and $10 \mathrm{~min}$ there was fall in DBP by $15.75 \%$ and $24.86 \%$ in group $\mathrm{P}$ and by $5.57 \%$ and $16.01 \%$ in group E respectively, which was not statistically significant.

Table 4: showing the changes in the mean arterial blood pressure

\begin{tabular}{|c|c|c|c|c|c|c|}
\hline & Group & $\begin{array}{c}\text { Mean } \\
\text { MAP mm } \\
\text { Hg }\end{array}$ & $\begin{array}{c}\text { Std. } \\
\text { Deviation }\end{array}$ & $\begin{array}{c}\text { Std. Error } \\
\text { Mean }\end{array}$ & $\begin{array}{l}\text { T test- } \\
\text { value }\end{array}$ & P-value \\
\hline \multirow{2}{*}{$\begin{array}{l}\text { Basal } \\
\text { MAP }\end{array}$} & Group P & 97.220 & 8.6432 & 1.2223 & \multirow{2}{*}{3.397} & \multirow{2}{*}{$0.001^{*}$} \\
\hline & Group E & 91.560 & 8.0055 & 1.1321 & & \\
\hline \multirow{2}{*}{$\begin{array}{l}\text { After } \\
\text { Fentanyl }\end{array}$} & Group P & 94.480 & 9.2079 & 1.3022 & \multirow{2}{*}{3.528} & \multirow{2}{*}{$0.001^{*}$} \\
\hline & Group E & 88.220 & 8.5244 & 1.2055 & & \\
\hline \multirow{2}{*}{$1 \mathrm{~min}$ AI } & Group P & 72.840 & 9.7087 & 1.3730 & \multirow{2}{*}{4.699} & \multirow{2}{*}{$0.000^{*}$} \\
\hline & Group E & 82.500 & 10.8200 & 1.5302 & & \\
\hline 3 min AI & Group P & 94.240 & 18.3376 & 2.5933 & 2.180 & * \\
\hline
\end{tabular}




\begin{tabular}{|c|c|c|c|c|c|c|}
\hline & Group E & 100.480 & 8.5601 & 1.2106 & & \\
\hline \multirow{2}{*}{$5 \min A I$} & Group P & 83.180 & 12.0402 & 1.7027 & \multirow{2}{*}{2.232} & \multirow{2}{*}{$0.028^{*}$} \\
\hline & Group E & 88.200 & 10.3923 & 1.4697 & & \\
\hline \multirow{2}{*}{$10 \min A I$} & Group P & 75.820 & 12.4486 & 1.7605 & \multirow{2}{*}{2.260} & \multirow{2}{*}{$0.026^{*}$} \\
\hline & Group E & 80.600 & 8.2833 & 1.1714 & & \\
\hline
\end{tabular}

After fentanyl and 1 min following induction there was fall in the MAP by $2.82 \%$ and $25.08 \%$ in group P and by $3.65 \%$ and $9.89 \%$ in group $E$ which were statistically significant with p value of 0.001 and 0.000 respectively. At 3 min ( laryngoscopy and intubation) MAP was 3.07\% less than the basal in group P and MAP increased by $9.74 \%$ in group $\mathrm{E}$ which were statistically significant with $\mathrm{p}=0.032$. At $5 \mathrm{~min}$ and $10 \mathrm{~min}$ MAP decreased by $14.44 \%$ and $22.01 \%$ in group $P$ and by $3.67 \%$ and $11.97 \%$ in group $E$ which were statistically significant with a $\mathrm{p}$ values of 0.028 and 0.026 respectively.

Table 5: showing incidence of pain on injection

\begin{tabular}{|l|c|c|c|c|}
\hline & Group P & Group E & $\begin{array}{c}\text { Chi-square } \\
\text { value }\end{array}$ & p-value \\
\hline Count & 14 & 4 & \multirow{2}{*}{4.521} & 0.030 \\
\hline \% within group & $28 \%$ & $8 \%$ & & \\
\hline
\end{tabular}

In our study we observed that $64 \%$ of the patients did not complain of any pain on injection. In Group P $28 \%$ of the patients and in group E $8 \%$ of the patients complained of pain on injection. Only one patient in Group P had severe pain. There was statistical difference between the two groups with $\mathrm{p}$ value 0.030 .

Table 6: showing the incidence of myoclonus

\begin{tabular}{|l|c|c|c|c|}
\hline & Group P & Group E & $\begin{array}{c}\text { Chi-square } \\
\text { value }\end{array}$ & p-value \\
\hline Count & 1 & 8 & \multirow{2}{*}{6.737} & \multirow{2}{*}{$0.009^{*}$} \\
\hline Incidence in \% & $2 \%$ & $16 \%$ & & \\
\hline
\end{tabular}

Myoclonus was not present in $82 \%$ of the patients. It was present in $2 \%$ of the patients in Group $\mathrm{P}$ and 16 $\%$ of the patients in group $\mathrm{E}$ which was statistically significant with a $\mathrm{p}$ value of 0.009 as shown in the above table.

Overall $86 \%$ of the patients had no PONV. It was seen in $14 \%$ of the patients with the incidence of $2 \%$ in propofol group and $12 \%$ in etomidate group with a $\mathrm{p}$ value of 0.040 which was statistically significant.

\section{Discussion}

Hemodynamic fluctuations during induction of general anaesthesia are a matter of concern for anesthesiologists. The usual response during laryngoscopy and intubation is increase in heart rate and arterial blood pressure due to stimulation of the sympathetic system. Most of the induction agents cause vasodilatation and myocardial depression which results in hypotension. This hypotension can be detrimental especially in patients with limited cardiovascular reserve. The main aim of our clinical study was to confirm the hemodynamic fluctuations of commonly used induction agents propofol and etomidate and their side effects like pain on injection, myoclonus at time of induction of general anaesthesia.

\section{Changes in heart rate}

The comparison of heart rate changes was done between two groups at 13,5 and 10 minutes following induction. The heart changes were statistically insignificant between the two groups.

Our results are comparable with the results obtained by Masoudifar M 6 et al. who compared hemodynamic response to laryngoscopy and tracheal intubation after using propofol and etomidate for induction of general anaesthesia.

\section{Changes in blood pressure}

Our study showed that propofol group had significantly decreased blood pressure (SBP, DBP and MAP) as compared to etomidate group. The previous studies have reported that fall in the arterial blood pressure by $25-40 \%$ following propofol induction. ${ }^{7}$ Our results are comparable with the results obtained by the study of Kaur $\mathrm{S}^{8}$ et al in their study SBP and DBP decreased in both the groups immediately after induction. But fall in SBP and DBP were significantly more in propofol group compared to etomidate group. Following laryngoscopy and intubation there was slight rise in blood pressure but it remained on lower side in propofol group as compared to etomidate group at 1, 3, and 5 min after intubation. SBP was significantly low in propofol group than etomidate group. In the study of Masoudifoar $\mathrm{M}^{6}$ et al there were significant differences between two groups regarding SBP, DBP and MAP. Patients of propofol group showed significant 
hypotension and etomidate group had more stable blood pressure as seen in our study.

In a study by Möller ${ }^{9}$ et al who used propofol and etomidate for induction of anaesthesia accompanied by monitoring of the MAP, cardiac index (CI) and systemic vascular resistance index (SVRI) values and they observed that propofol significantly reduced the MAP and inhibited sympathetic excitation.

\section{Pain on Injection}

In the study of Kaur $S^{8}$ et al, they found pain on injection in $26.7 \%$ in the group $\mathrm{P}$ and $6.7 \%$ in group $\mathrm{E}$. In our study incidence was $28 \%$ and $8 \%$ respectively. In both the cases incidence of pain on injection was significantly higher in group $\mathrm{P}$ which tally with each other.

\section{Myoclonus}

The incidence of myoclonus with etomidate induction is $0-70 \%{ }^{10}$ It can be of a concern in full stomach patients, in penetrating eye injuries, high intraocular pressure. Ko $\mathrm{B}^{11}$ et al studied the incidence of myoclonus after etomidate induction using fentanyl and remifentanil as premedicants. In fentanyl and etomidate group they found incidence of myoclonus $6.7 \%$.

The incidence of myoclonus in our study using fentanyl and etomidate was $16 \%$. In fentanyl and propofol group incidence of myoclonus was $2 \%$ which was higher in our study. Reason could be that they have used etomidate $0.2 \mathrm{mg} / \mathrm{kg}$ body weight compared to $0.3 \mathrm{mg} / \mathrm{kg}$ body weight in our study. As it is known that myoclonus is dose dependent. In Kaur S 8 et al incidence of myoclonus was $16.7 \%$ in etomidate group and $0 \%$ in propofol group. These findings are comparable to our results $16 \%$ and $2 \%$ respectively.

\section{PONV}

$\mathrm{Wu} \mathrm{J}^{12}$ et al found that in the propofol group PONV was $2.5 \%$, where as in etomidate group was 50 $\%$.This exaggerated PONV in etomidate group cannot be explained, whereas incidence in propofol group was comparable with our results. Ultimately proving that incidence of PONV is higher with etomidate compared to propofol, which can be attributed to antiemetic property of propofol.

\section{Conclusion}

We conclude that etomidate is haemodynamically more stable compared to propofol as the incidence and the severity of hypotension are higher with propofol, but only drawback was high incidence of myoclonus. We therefore suggest that etomidate is a better option in patients particularly prone to hemodynamic instability at induction like uncontrolled hypertension, septic, critically ill and patients with coronary artery disease.

\section{References}

1. Harris CE, Murray M, Anderson AM, Grounds RM, Morgan M. Effects of thiopentone and propofol on the hemodynamic response to tracheal intubation. Anaesthesia 1988;43:32-6.

2. Gooding JM, Corssen G. Effect of etomidate on the cardiovascular system. Anesth Analg 1977;56:717-9.

3. Ray DC, McKeown DW. Effect of induction agent on vasopressor and steroid use, and outcome in patients with septic shock. Crit Care. 2007;11:56.

4. Zausig YA, Busse H, Lunz D, et al. Cardiac effects of induction agents in the septic rat heart. Crit Care. 2009;13:144.

5. Ray DC, McKeown DW. Etomidate for critically ill patients. Pro: yes we can use it. Eur J Anaesthesiol. 2012;29:506-10.

6. Masoudifar M, Beheshtian E. Comparison of cardiovascular response to laryngoscopy and tracheal intubation after induction of anesthesia by Propofol and Etomidate. J Res Med Sci. 2013 Oct;18(10):870-4.

7. Larsen R, Rathgeber J, Bagdahn A, et al: Effects of propofol on cardiovascular dynamics and coronary blood flow in geriatric patients: A comparison with etomidate. Anaesthesia 1988;43(Suppl):25-31.

8. Kaur S, Kataria AP, Kaur G, Kaur M, Attri JP, Mohan B. Comparison of Induction Characteristics of Propofol-Lipuro and Etomidate-Lipuro in Cardiac Patients in Non- cardiac Surgery. Int J Sci Stud 2014;2(6):66-72.

9. Moller Petrun A, Kameni K. Bispectral index-guided induction of general anaesthesia in patients undergoing major abdominal surgery using propofol or etomidate: a double-blind, randomized, clinical trial. Br J Anaesth 2013 Mar;110(30):388-96.

10. Luan HF, Zhao ZB, Feng JY, et al. Prevention of etomidate-induced myoclonus during anesthetic induction by pretreatment with dexmedetomidine. Brazilian Journal of Medical and Biological Research. 2015;48(2):186-90.

11. Ko B, Oh J, Lee J, Choi S, Lee S, Chung C. Comparison of effects of fentanyl and remifentanil on hemodynamic response to endotracheal intubation and myoclonus in elderly patients with etomidate induction. Korean Journal of Anesthesiology. 2013;64(1):12.

12. Wu J, Yao S, Wu Z, Wu Z, Chu S, Xia G et al. A comparison of anesthetic regimens using etomidate and propofol in patients undergoing first-trimester abortions: double-blind, randomized clinical trial of safety and efficacy. Contraception. 2013;87(1):55-62. 